\title{
Predicting change in symptoms and function in patients with persistent shoulder pain: a prognostic model development study
}

Mathias Moselund Rønnow*, Thor André Brøndberg Stæhr and David Høyrup Christiansen

\begin{abstract}
Background: Persistent shoulder pain causes considerable disruption of the individual's life and imposes high costs on healthcare and society. Well-informed treatment and referral pathways are crucial as unsuccessful interventions and longer duration of symptoms minimizes the likelihood of success in future interventions. Although physiotherapy is generally recommended as first line treatment, no prognostic model or clinical prediction rules exists to help guide the treatment of patients with persistent shoulder pain undergoing physiotherapy. Thus, the objective of this study was to develop a prognostic model to inform clinical decision making and predict change in symptoms and function in patients with persistent shoulder pain.
\end{abstract}

Methods: This was a prospective cohort study of 243 patients with persistent shoulder pain referred to outpatient physiotherapy rehabilitation centres. Data was collected at baseline and six-month follow-up. The outcome was change in shoulder symptoms and function as measured by the shortened version of the Disabilities of the Arm, Shoulder and Hand questionnaire (QuickDASH) from baseline to 6 months follow up. Potential predictors were included in a multivariable linear regression model which was pruned using modified stepwise backwards elimination.

Results: The final model consisted of seven predictors; baseline QuickDASH score, employment status, educational level, movement impairment classification, self-rated ability to cope with the pain, health-related quality of life and pain catastrophizing. Together these variables explained 33\% of the variance in QuickDASH-change scores with a model root mean squared error of 17 points.

Conclusion: The final prediction model explained 33\% of the variance in QuickDASH change-scores at 6 months. The root mean squared error (model SD) was relatively large meaning that the prediction of individual change scores was quite imprecise. Thus, the clinical utility of the prediction model is limited in its current form. Further work needs be done in order to improve the performance and precision of the model before external validity can be examined along with the potential impact of the model in clinical practice. Two of the included predictors were novel and could be examined in future studies; movement impairment classification based on diagnosis and health-related quality of life.

Keywords: Prognosis, Prediction, Prognostic model, Exercise, Physical therapy, Physiotherapy, Shoulder pain, Chronic shoulder pain, Persistent shoulder pain, Shoulder disorders

\footnotetext{
* Correspondence: mathro@rm.dk

Department of Occupational Medicine, University Research Clinic, Regional

Hospital West Jutland, Gl. Landevej 61, 7400 Herning, Denmark
}

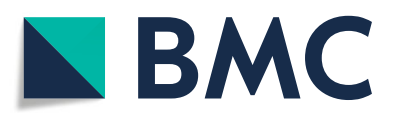

(c) The Author(s). 2021, corrected publication 2021. Open Access This article is licensed under a Creative Commons Attribution 4.0 International License, which permits use, sharing, adaptation, distribution and reproduction in any medium or format, as long as you give appropriate credit to the original author(s) and the source, provide a link to the Creative Commons licence, and indicate if changes were made. The images or other third party material in this article are included in the article's Creative Commons licence, unless indicated otherwise in a credit line to the material. If material is not included in the article's Creative Commons licence and your intended use is not permitted by statutory regulation or exceeds the permitted use, you will need to obtain permission directly from the copyright holder. To view a copy of this licence, visit http://creativecommons.org/ licenses/by/4.0/. The Creative Commons Public Domain Dedication waiver (http://creativecommons.org/publicdomain/zero/1. 0/) applies to the data made available in this article, unless otherwise stated in a credit line to the data. 


\section{Background}

Shoulder pain is one of the most common musculoskeletal complaints in the general population and can mostly be managed in primary care $[1,2]$. However, more than half of the people presenting with a new episode of shoulder pain develop persistent symptoms, which can lead to considerable disruption of the individual's life [3, 4]. The patients who do not respond favourably to treatment in primary care are commonly referred to orthopaedic evaluation in secondary care $[5,6]$. For common shoulder disorders, clinical guidelines recommend at least 3 months of physiotherapy with exercise before surgery is considered, which in Denmark frequently includes referral to the municipal outpatient rehabilitation centres [7]. As the patients have undergone longer care trajectories prior to the municipal rehabilitation (general practitioner - secondary care - municipal rehabilitation), they typically present with persistent symptoms and complications. Further unsuccessful treatment increases the likelihood of persistent symptoms and reduces the effectiveness of future interventions [8]. This can lead to both higher tangible and intangible costs (e.g. loss of quality of life), which is problematic for patients, clinicians, and for society [4, 9]. The economic impact of a relatively small amount of unsuccessfully rehabilitated patients was underlined in a study from Sweden, that estimated that one-fifth of shoulder patients were responsible for $91 \%$ of the total tangible costs [9]. To optimize the use of scarce resources and to improve the outcomes of these patients, it is necessary to gain a greater knowledge about which factors predict the prognosis of shoulder patients with persistent symptoms. A series of important prognostic factors can be combined in a prognostic model to predict future outcomes [10-14]. Based on the model, clinical prediction rules can be developed in order to tailor interventions to the individual patient and subgroups [10-14]. These can then be tested in intervention studies and can potentially lead to new and more effective treatment and referral pathways to the benefit of the patient and society. In recent years, several studies reporting on prognosis and prognostic models for shoulder patients undergoing physiotherapy have been published [15-23]. However, there is a lack of models with the potential to be used in clinical practice - especially in patients with long-term symptoms [15-17, 19-22].

Thus, the aim of this study was to develop a prognostic model to inform clinical decision making and predict change in symptoms and function in patients with persistent shoulder pain referred to outpatient physiotherapy rehabilitation.

\section{Methods}

\section{Design and study population}

This prospective cohort study was performed at six municipal outpatient rehabilitation centres in West Jutland,
Denmark. From February 2018 to August 2019 consecutive patients referred for physiotherapy with shoulder pain were invited to participate. Inclusion criteria were: Age above 18 years, adequate understanding of the Danish language to complete questionnaires, and referral to physiotherapy as a part of conservative treatment. All patients received a confirmation letter on their rehabilitation referral along with written information about the project via their secure digital mailbox (e-Boks.dk) where Danish citizens receive all letters from public authorities [24, 25]. If agreeing to participate, the patients were asked to complete an online questionnaire before their first consultation. They were notified by email when follow-up questionnaires at two-, four- and six- months were available. Data collection was administrated by an online clinical database, Trial Partner (https://trialparner.clin.au.dk).

No attempts were made to control treatment, which was left up to the physiotherapist's discretion. The study was approved by the Danish Data Protection Agency (no 1-16-02-9-18) and as referral and treatment pathways were unaffected by participation in the study, under Danish law, no ethics approval was needed (Act on Research Ethics Review of Health Research Projects, October 2018) [26].

Reporting of the present study follows the TRIPOD statement [27, 28].

\section{Outcome variable}

The main outcome of interest was change in symptoms and function over 6 months (baseline score minus follow up score) as measured by the Danish version of the Quick Disabilities of the Arm, Shoulder and Hand questionnaire (QuickDASH). The QuickDASH is a patient reported outcome measure that measures physical function and symptoms of the upper extremity through 11 items. Scores are converted to a scale of zero to 100 where zero represents no symptoms and disability and 100 represents maximum symptoms and disability. The QuickDASH has been found to be acceptable, valid, reliable and responsive in various shoulder and upper-extremity patients [29-34].

\section{Candidate predictors}

The selection of candidate predictors was based on previous literature and included sociodemographic, psychological and clinical characteristic variables (Table 1) $[17,19,20,35]$. In addition to predictors from previous literature, three variables that had not been examined in shoulder patients before were included for modelling: Health-related quality of life, self-rated risk of persistent symptoms and movement impairment classification. We decided a priory to categorise diagnosis into movement impairments based on the work by Ludewig et al. since limited prognostic value has been found for most shoulder diagnoses (see Table 1) [36]. All candidate predictors 
Table 1 Candidate predictor overview

\begin{tabular}{|c|c|c|}
\hline Predictor & Collection method/ source & Specification and/or categories \\
\hline \multicolumn{3}{|l|}{ Sociodemographics } \\
\hline Age & Unique identifier (CPR number) ${ }^{\mathrm{a}}$ & Years \\
\hline Sex & Unique identifier (CPR number) ${ }^{\mathrm{a}}$ & Male or female \\
\hline Professional educational level & Baseline questionnaire & $\begin{array}{l}\text { None, short-cycle higher education }<21 / 2 \text { years, medium-cycle higher } \\
\text { education } 31 / 2-4 \text { years, long-cycle higher education }>4 \text { years, other }\end{array}$ \\
\hline Employment status & Baseline questionnaire & $\begin{array}{l}\text { Employed, subsidised employment, leave of absence, unemployed, } \\
\text { student/ apprentice/ vocational training, early retiree/ retiree/ } \\
\text { voluntary early retiree, other }\end{array}$ \\
\hline \multicolumn{3}{|l|}{ Clinical characteristics } \\
\hline QuickDASH & Baseline questionnaire & As in "outcome variable" \\
\hline Duration of symptoms & Baseline questionnaire & Months \\
\hline Pain intensity & $\begin{array}{l}\text { Baseline questionnaire; Numeric pain rating } \\
\text { scale (NPRS) [37-39] }\end{array}$ & $\begin{array}{l}\text { Typical shoulder pain the last } 14 \text { days ranging from } 0 \text { "no pain" } \\
\text { to } 10 \text { "worst pain imaginable }\end{array}$ \\
\hline Sick leave & Baseline questionnaire & $\begin{array}{l}\text { Whole days with any sick leave due to current episode of } \\
\text { shoulder pain }\end{array}$ \\
\hline $\begin{array}{l}\text { Movement impairment } \\
\text { classification }\end{array}$ & $\begin{array}{l}\text { Pathoanatomic diagnosis was assessed by the } \\
\text { physiotherapist at first consultation and based } \\
\text { on that, the patients were classified in } \\
\text { movement impairment groups after data } \\
\text { collection [36] }\end{array}$ & $\begin{array}{l}3 \text { groups based on movement impairment: Hypomobility } \\
\text { (capsulitis, arthritis, post fracture etc.), Hypermobility (instability, } \\
\text { trauma etc.), and Aberrant motion (rotator cuff, impingement, } \\
\text { pain with movement etc.) }\end{array}$ \\
\hline \multicolumn{3}{|c|}{ Pain behaviour and psychological factors } \\
\hline Fear avoidance & $\begin{array}{l}\text { Baseline questionnaire; two questions from the } \\
\text { Danish short form version of Örebro } \\
\text { Musculoskeletal pain questionnaire [40-44] }\end{array}$ & $\begin{array}{l}\text { Two questions ranging from } 0 \text { to } 10(0=\text { no fear avoidance, } \\
10=\text { high fear avoidance) with a sum score from } 0 \text { to } 20\end{array}$ \\
\hline $\begin{array}{l}\text { Self-rated ability to cope with } \\
\text { the pain }\end{array}$ & $\begin{array}{l}\text { Baseline questionnaire; one questions from the } \\
\text { Danish version of Örebro Musculoskeletal pain } \\
\text { questionnaire [40-44] }\end{array}$ & $\begin{array}{l}\text { One question ranging from } 0 \text { to } 10(0=\text { no ability, } \\
10=\text { complete ability) }\end{array}$ \\
\hline $\begin{array}{l}\text { Self-rated risk of the pain } \\
\text { becoming persistent }\end{array}$ & $\begin{array}{l}\text { Baseline questionnaire; one question from the } \\
\text { Danish version of Örebro Musculoskeletal pain } \\
\text { questionnaire [40-44] }\end{array}$ & $\begin{array}{l}\text { One question ranging from } 0 \text { to } 10(0=\text { no risk, } 10=\text { very } \\
\text { large risk) }\end{array}$ \\
\hline Pain catastrophizing & $\begin{array}{l}\text { Baseline questionnaire; two questions from the } \\
\text { pain catastrophizing scale [45-48] }\end{array}$ & $\begin{array}{l}\text { Two questions ranging from } 0 \text { to } 10 \text { with a sum score from } \\
0 \text { to } 20(0=\text { no pain catastrophizing, } 20=\text { high pain } \\
\text { catastrophizing) }\end{array}$ \\
\hline Mental wellbeing & $\begin{array}{l}\text { Baseline questionnaire; WHO Mental wellbeing } \\
\text { Index (WHO-5) [49] }\end{array}$ & $\begin{array}{l}\text { A five-item questionnaire with a sum score ranging from } 0 \\
\text { (low mental wellbeing) to } 100 \text { (high mental wellbeing) }\end{array}$ \\
\hline Health-related quality of life & EQ 5D-5L index $[50,51]$ & $\begin{array}{l}\text { The index contains five dimensions each assessed by one } \\
\text { question regarding; mobility, self-care, usual activities, } \\
\text { pain/discomfort and anxiety/depression [52]. Utility values } \\
\text { derived from a general population sample is used to calculate an } \\
\text { index score ranging from - } 0.6 \text { to } 1 \text {, where } 1 \text { represents a perfect } \\
\text { health-related quality of life [52-54]. }\end{array}$ \\
\hline
\end{tabular}

${ }^{a}$ CPR numbers contain information on both sex and age [55]

were collected by a baseline questionnaire and registration forms from first consultation. Thus, the model was designed to predict expected change in symptoms and function over 6 months at first consultation.

\section{Statistical analysis}

\section{Sample size}

As a result of the multivariable nature of prognostic modelling studies, it is difficult to estimate the required sample size [11]. Thus, the number of variables allowed for inclusion was based on the assumption that at least
10 subjects are needed per degree of freedom in the model $[11,56]$.

\section{Descriptive statistics and missing data}

The baseline population was described by percentages and means, and by medians when numerical variables were not normally distributed. Number of missing values, follow-up response rate and differences in baseline characteristics between responders and nonresponders were calculated. Candidate predictors with missing values $>10 \%$ were discarded since the problem 
is likely to recur when using the model in clinical practice [12]. Further, patients with missing values in included predictors were excluded.

\section{Prognostic modelling}

The prognostic modelling was performed by pruning a full multiple linear regression model which included all the candidate predictors using modified backwards elimination. Model performance was assessed by the adjusted coefficient of determination (adjusted $\mathrm{R}^{2}$ ), which summarizes the predictive ability of a normal-error model through its explained variance (in this case variance in QuickDASH-change) adjusting for number of included variables relative to the number of data points $[14,57,58]$.

Pruning was done by:

1) Presuming overlap in predictor information based on the literature and clinical reasoning [28]. To get an indication of whether the presumption was fair, the correlation between variables was examined with Spearman's correlation, since high correlations indicate that one of the variables does not add much to the prediction [12]. Variables were eliminated only if it did not lead to a drop in the adjusted $\mathrm{R}^{2}$.

2) When no more presumptions were present, correlations, standardized coefficients and $p$-values were used to eliminate the next variable [57]. Deletion of a variable could not lead to a higher drop in the adjusted $R^{2}$ value than $0.5 \%$.

Before pruning, two variables, employment status and professional educational level, were each collapsed into three categories to reduce the number of degrees of freedom of the full model. From diagnostic plots, both the full and the final model were deemed in line with the assumptions of multiple linear regression. Internal validation was performed by bootstrapping the final model (10.000 reps) to obtain a confidence interval for the adjusted $R^{2}$.

A sensitivity analysis was performed to examine the model's robustness to extreme QuickDASH changescores in patients lost to follow up: The prognostic modelling was carried out on two scenarios: A best case scenario where patients with missing change-scores were assigned predicted 6 months change-scores plus the minimal important change (MIC) of 13.6 points, and a worst case scenario where the MIC was subtracted from the predicted change scores [31]. The performance of the final model was compared to the performance of a parsimonious model including only baseline QuickDASH as a predictor and a supplementary analysis was performed using Akaike's information criteria instead of the adjusted coefficient of determination for the backwards elimination [59]. To allow for comparison across supplementary models we only included participants without missing information in predictors. All statistical analyses were performed using Stata Version 16.1 (StataCorp LP, College Station, TX, USA).

\section{Results}

\section{Recruitment and population data}

In total, 668 patients were referred of which 51 were excluded as they were not registered with a secure digital mailbox. Of the 617 invited patients, 317 agreed to participate. Five of these were excluded due to non-eligible diagnoses; two were referred with cancer and three with neurological diseases. This left 312 patients for the study, of which $243(78 \%)$ returned the six-month follow-up questionnaire (see Fig. 1). Non-responders were younger and less likely to be retired and had a longer duration of symptoms and a poorer self-rated ability to cope with the shoulder pain. Furthermore, they tended to have lower levels of education and poorer mental wellbeing. An additional file describes the differences in more detail (see Additional file 1). Baseline characteristics of included patients $(n=312)$ are shown in Table 2 . For responders, the average QuickDASH improvement from first consultation to 6 months follow up was 12.9 (95\%CI: 10.4; 15.5).

\section{Missing values}

No candidate predictor, except for sick leave, had more missing values than $3.8 \%$ and the distribution appeared random. The following missing values were observed: Professional educational level: 1 (0.3\%), baseline QuickDASH: 2 (0.6\%), duration of symptoms: $12(3.8 \%)$, sick leave: 103 (33\%), fear avoidance: 5 (1.6\%), coping: 10 (3.2\%), pain catastrophizing: 7 (2.2\%), risk of persistent symptoms: 9 (2.9\%), mental health: 11 (3.5\%), healthrelated quality of life: 10 (3.2\%). In total, 15 patients were not included in the final model due to missing information in predictors.

\section{Prognostic modelling}

The full model explained $30.8 \%$ of the variance in QuickDASH change. Parameters are presented in Table 3. After backwards elimination, seven predictors explained 33.3\% of the variance: Baseline QuickDASH, employment status, professional educational level, movement impairment classification, self-rated ability to cope with the pain, health-related quality of life and pain catastrophizing. The parameters are presented in Table 4 followed by a practical example on how to calculate predicted change scores. The parsimonious model is presented in Table 5. Further details on model development can be found in Additional file 2. Internal validation by bootstrapping produced a 95\% confidence interval of 23 to $43 \%$. The sensitivity analysis using both a best and worst case scenario to include patients lost to follow up (i.e. predicted values $+/-$ MIC), did not change which 


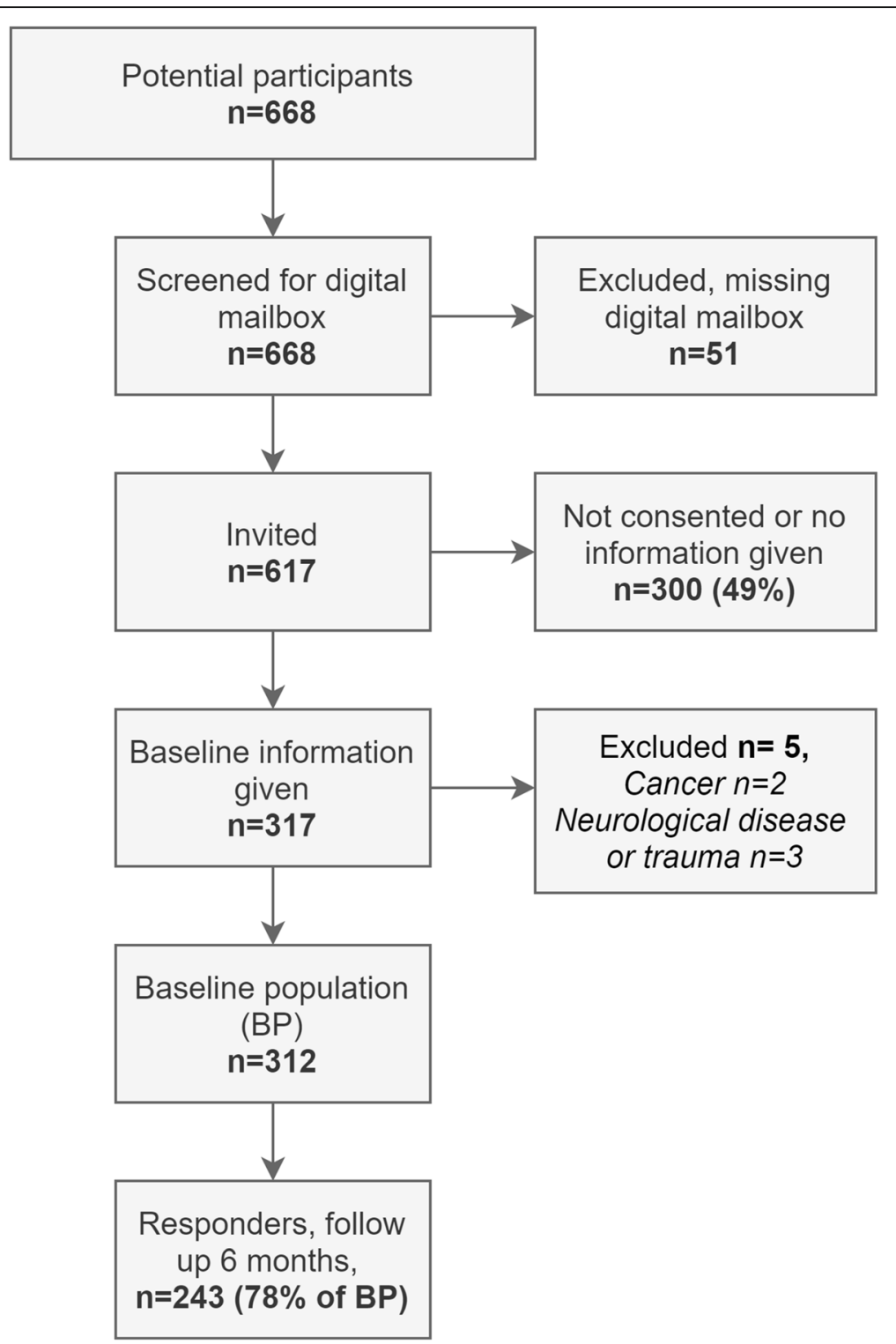

Fig. 1 Flow diagram of participant recruitment

candidate predictors were included during the model development, with one exception, as age added predictive value in the best case analysis. The supplementary analysis using Akaike's information criterion instead of the adjusted coefficient of determination led to a slightly different model with duration of symptoms being added to the model. Model performance was marginally better in the model derived from Akaike's information criterion $(n=220)$. The model performance measures are presented in Table 5 and the parameters from all supplementary analyses are presented in Additional file 3.

The model was designed to calculate the expected improvements for patients at the first consultation so that the treatment trajectory can be adapted from this information.
Model to calculate predicted change in QuickDASH for a given patient:

$\triangle$ QuickDASH $=0.61 \times$ baselineQuickDASH-11.12 $\times$ unempl. $/$ subsid. $/$ sick$0.22 \times$ pensioner $+6.03 \times$ low/vocational education $+0.94 \times$ medium $/$ high education-10.36 $\times$ Hypermobility $-8.57 \times$ Aberrant motion + $1.28 \times$ coping $+12.1 \times H Q O L-0.45 \times$ Pain catastrophizing-19.91

Note, that categorical variables are scored 0 or 1 depending on which group represents the individual patient. Below are two examples of how to score the model for two different patients with the same baseline QuickDASH (we chose the population mean):

Patient A characteristics: Baseline QuickDASH $=42$. Employment status $=$ Studying. Professional educational level $=$ Low. Movement impairment classification $=$ 
Table 2 Selected summary baseline characteristics of participants $(n=312)$

\begin{tabular}{ll}
\hline Factor & Value \\
\hline Sociodemographics & \\
Age in years, mean (SD) & $54(14.6)$ \\
Female, $n$ (\%) & $193(61.9)$ \\
Professional educational level, $\mathrm{n}(\%)$ & \\
Unskilled & $47(15.0)$ \\
Lower level, < 3years & $46(14.7)$ \\
Vocational and training & $123(39.3)$ \\
Medium level, > 3-4years & $80(25.6)$ \\
Higher level, > 4years & $16(5.1)$ \\
Employment status, $\mathrm{n}$ (\%) & \\
Employed & $155(49.5)$ \\
Subsidised employment & $18(5.8)$ \\
On leave & $2(.6)$ \\
Unemployed & $10(3.2)$ \\
Student/under training & $15(4.8)$ \\
Retired & $99(31.6)$ \\
Other & $13(4.2)$
\end{tabular}

Clinical characteristics

QuickDASH 0-100 score, mean (sd)

Duration of symptoms in months, mean (sd)

Median (iqr)

$29.4(52.2)$

$10(25)$

Pain, NPRS 0-10 mean (sd)

$5.5(2.3)$

Sick leave, whole or part days ${ }^{\mathrm{a}}$, mean (sd)

Median (iqr)

$18.0(38.0)$

0 (14)

Movement impairment classification n (\%)

Hypomobility

Hypermobility

Aberrant motion

$193(61.9)$

Pain behaviour and psychological factors

Fear avoidance 0-20 score, mean (sd)

$13.7(7.4)$

Pain catastrophizing, 0-20 score, mean (sd)

$7.7(5.4)$

Self- rated ability to cope, 0-10 score, mean (sd)

$5.9(2.4)$

Self-rated risk of persistent symptoms, 0-10, mean (sd)

Mental wellbeing, 0-100 score, mean (sd)

Health-related quality of life, $-0,6-1$ score, mean (sd)

Median (iqr)

$5.9(3.0)$

$56.9(22.9)$

$0.67(0.15)$

$0.69(0.16)$

Numerical variables with normally distributed data are described by means and standard deviation. Numerical variables with data not normally distributed are described by both means with standard deviations and medians with interquartile ranges

Abbreviations: $s d$ standard deviation, iqr inter quartile range, NPRS Numeric pain rating scale, QuickDASH Quick Disabilities of the arm, shoulder and hand aDue to current episode of shoulder pain

Hypomobility. Self-rated ability to cope with the pain = 9. Health-related quality of life $=0.9$. Pain catastrophizing $=3$.
Patient B characteristics: Baseline QuickDASH $=42$. Employment status $=$ Unemployed. Professional educational level $=$ None. Movement impairment classification = Aberrant motion. Self-rated ability to cope with the pain $=2$. Health-related quality of life $=0.4$. Pain catastrophizing $=17$.

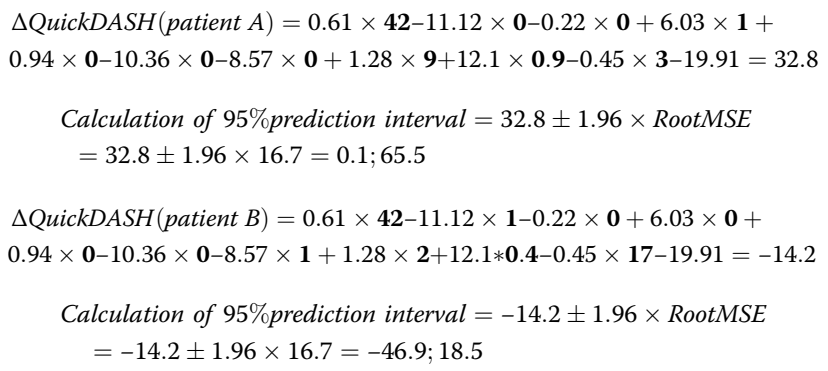

Thus, from first consultation to 6 months follow up, patients with the characteristics of patient A are expected to gain a 33-point QuickDASH improvement (95\%PI: 0; 66) while patients with the characteristics of patient $\mathrm{B}$ are expected to experience worse symptoms and function corresponding to a rise of 14 points on the QuickDASH (95\% PI: - 47; 19) despite treatment. In this case, patient A could continue the planned course of physiotherapy while patient B probably would need other or supplementary treatment in order to improve. In more moderate cases, e.g. an expected change of 12 points, the clinician would have to judge whether this improvement would be sufficient to continue usual treatment in coherence with the patient. This judgement could depend on the choice of minimal clinical important difference threshold which ranges from 8 to 16 depending on methodology, setting and subpopulation $[60,61]$ and the patient's motivation for treatment etc. Thus, the numerical nature of this prognostic model allows for more individual judgement in each patientcase. However, the uncertainty of the predictions reflected in the root MSE and the 95\% prediction intervals must be noted.

\section{Discussion}

Principal findings and comparison with existing literature The final prognostic model explained $33.3 \%$ of the variance in QuickDASH change scores with a root mean squared error of 16.7. It included seven predictors; baseline QuickDASH score, employment status, professional educational level, movement impairment classification, self-rated ability to cope with the pain, health-related quality of life and pain catastrophizing.

In line with previous research, we found higher baseline disability and symptoms to be associated with greater improvement, whereas higher pain catastrophizing, lower educational level and unemployment/sick 
Table 3 Parameters for the full multivariable linear regression model $(n=220)$

\begin{tabular}{|c|c|c|c|}
\hline Variable & Coefficient & $95 \% \mathrm{Cl}$ & Stand. coefficient \\
\hline Baseline QuickDASH & 0.62 & $0.41 ; 0.83$ & 0.60 \\
\hline Age & -0.10 & $-0.33 ; 0.13$ & -0.06 \\
\hline \multicolumn{4}{|l|}{ Sex } \\
\hline Woman & Ref. & & \\
\hline Man & -0.39 & $-5.44 ; 4.65$ & -0.01 \\
\hline \multicolumn{4}{|l|}{ Employment status } \\
\hline Employed/studying & Ref. & & \\
\hline Unemployed/ subsidised employment/ sick leave & -10.89 & $-18.86 ;-2.92$ & -0.17 \\
\hline Pensioner & 1.86 & $-4.65 ; 8.38$ & 0.04 \\
\hline \multicolumn{4}{|l|}{ Professional educational level } \\
\hline No education & Ref. & & \\
\hline Low $(<2)$ or vocational & 6.33 & $-0.57 ; 13.24$ & 0.15 \\
\hline Medium (3) or high (> 4) & 1.81 & $-5.58 ; 9.20$ & 0.04 \\
\hline \multicolumn{4}{|l|}{ Movement impairment classification } \\
\hline Hypomobility & Ref. & & \\
\hline Hypermobility & -10.10 & $-17.60 ;-2.60$ & -0.19 \\
\hline Aberrant motion & -8.16 & $-14.67 ;-1.64$ & -0.20 \\
\hline Pain & -0.04 & $-1.42 ; 1.34$ & -0.005 \\
\hline Duration of symptoms & -0.05 & $-0.10 ; 0.01$ & -0.11 \\
\hline Self-rated ability to cope with the pain & 1.20 & $-0.01 ; 2.41$ & 0.14 \\
\hline Fear avoidance & -0.08 & $-0.68 ; 0.52$ & -0.02 \\
\hline Health-related quality of life & 12.9 & $-12.6 ; 38.2$ & 0.09 \\
\hline Mental wellbeing & 0.00 & $-0.14 ; 0.14$ & 0.00 \\
\hline Self-rated risk of persistent symptoms & 0.06 & $-1.00 ; 1.11$ & 0.01 \\
\hline Pain catastrophizing & -0.37 & $-0.95 ; 0.21$ & -0.10 \\
\hline Intercept & -14.28 & $-42.44 ; 13.87$ & - \\
\hline \multicolumn{4}{|c|}{$\begin{array}{l}\text { Adjusted coefficient of determination, adjusted } R^{2}=30.8 \% \\
\text { Root } \mathrm{MSE}^{\mathrm{a}}=17.12\end{array}$} \\
\hline
\end{tabular}

Positive coefficients reflect a decrease in QuickDASH equal to better function and less symptoms. The model had 17 degrees of freedom, corresponding to 13 participants per degree of freedom

Abbreviations: QuickDASH Quick Disabilities of the arm, shoulder and hand, $\mathrm{Cl}$ confidence interval

${ }^{\text {a }}$ Model standard deviation

leave/working a subsidised job was associated with less improvement $[8,62]$. As previous literature, we found limited predictive value of sex [62].

In contrast to other studies, we found self-rated ability to cope with the pain to be associated with larger improvement, while age, pain (NPRS), mental wellbeing and fear avoidance showed limited predictive value $[8$, 15]. These differences might be explained by variation in design, outcome measures, inclusion criteria, setting and by the fact that most previous studies included patients with shorter duration of symptoms than of those in the present study.

Our model included two predictors that have not been examined in shoulder patients before. Although not reaching statistical significance, health-related quality of life explained a noteworthy amount of the variance in the QuickDASH change scores. Furthermore, movement impairment classification had a strong association with QuickDASH change scores in our model, where hypomobility was associated with a greater improvement than hypermobility and aberrant motion. To our knowledge, such diagnostic classifications have not previously been shown predictive in shoulder patients [19]. Thus, movement impairment classification should be examined in future prognostic studies. The relevance of our prediction model was supported by the fact that it consisted of biological, psychological and social factors and it was therefore theoretically in line with the main categories of the biopsychosocial model [63]. 
Table 4 Parameters for the final multivariable linear regression model $(n=229)$

\begin{tabular}{|c|c|c|c|}
\hline Variable & Coefficient & $95 \% \mathrm{Cl}$ & Stand. coefficient \\
\hline Baseline QuickDASH & 0.61 & $0.44 ; 0.78$ & 0.59 \\
\hline \multicolumn{4}{|l|}{ Employment status } \\
\hline Employed/studying & Ref. & & \\
\hline Unemployed/subsidised employment/ sick leave & -11.12 & $-18.63 ;-3.60$ & -0.17 \\
\hline Pensioner & -0.22 & $-5.10 ; 4.66$ & -0.01 \\
\hline \multicolumn{4}{|l|}{ Professional educational level } \\
\hline No education & Ref. & & \\
\hline Low $(<2)$ or vocational & 6.03 & $-0.42 ; 12.49$ & 0.15 \\
\hline Medium (3) or high (> 4) & 0.94 & $-5.92 ; 7.79$ & 0.02 \\
\hline \multicolumn{4}{|l|}{ Movement impairment classification } \\
\hline Hypomobility & Ref. & & \\
\hline Hypermobility & -10.36 & $-17.44 ;-3.28$ & -0.19 \\
\hline Aberrant motion & -8.57 & $-14.50 ;-2.63$ & -0.21 \\
\hline Self-rated ability to cope with the pain & 1.28 & $0.17 ; 2.40$ & 0.14 \\
\hline Health-related quality of life ${ }^{a}$ & 12.1 & $-10.5 ; 34.8$ & 0.09 \\
\hline Pain catastrophizing & -0.45 & $-0.94 ; 0.04$ & -0.12 \\
\hline Intercept & -19.91 & $-42.57 ; 2.76$ & - \\
\hline $\begin{array}{l}\text { Adjusted coefficient of determination, adjusted } R^{2}=33.3 \% \\
\text { Root } \mathrm{MSE}^{\mathrm{a}}=16.7\end{array}$ & & & \\
\hline
\end{tabular}

Positive coefficients reflect a decrease in QuickDASH equal to better function and less symptoms. The model had 10 degrees of freedom, corresponding to 23 participants per degree of freedom

Abbreviations: QuickDASH Quick Disabilities of the arm, shoulder and hand, $\mathrm{Cl}$ confidence interval

${ }^{\text {a }}$ Model standard deviation

\section{Strengths and limitations}

The prospective design adds to the strengths of this study along with the rigorous reporting of the prognostic modelling which allows replication of the study methods (Additional file 2). Also, we based the elimination process on presumptions from clinical rationale and the literature, rather than on conventional significance levels [13].

In a sensitivity analysis, we examined the possible impact of potential attrition bias since $22 \%$ the included participants did not provide outcome data at 6 months. The sensitivity analysis showed that the model did not change when extreme values were assigned to the dropouts except in a best-case scenario where age was included. Thus, the model was robust to such potential attrition biases, but age could possibly hold prognostic value depending on the true change scores of the dropouts. A supplementary analysis using Akaike's information criterion for backwards elimination instead of the adjusted coefficient of determination led to a model including duration of symptoms. Thus, duration of symptoms could potentially hold prognostic value in the model (resulting in marginal improvement in model performance). As we had 13 participants per degree of freedom in the full model, our sample size was in line with suggested rules of thumb of having more than ten participants per degree of freedom [11, 56]. However, a larger sample size would have been preferable and could potentially lead to differences in the model.

The use of self-reported data could potentially have caused information problems since patients might

Table 5 Performance compared over models $(n=220)$

\begin{tabular}{|c|c|c|c|}
\hline Model & Adj. $\mathrm{R}^{2}(95 \% \mathrm{Cl})$ & AIC value & Root MSE \\
\hline Final model derived from adj. $R^{2}$ & $32 \%(22 ; 42)$ & 1881 & 17.0 \\
\hline Final model derived from $\mathrm{AlC}^{\mathrm{a}}$ & $32.5 \%(22 ; 43)$ & 1880 & 16.9 \\
\hline Parsimonious model using only baseline QuickDASH as predictor & $19 \%(10 ; 29)$ & 1909 & 18.47 \\
\hline Model without independent variables & - & - & 20.58 \\
\hline
\end{tabular}

Abbreviations: $A d j . R^{2}$ adjusted coefficient of determination, $C$ confidence interval, AIC Akaike's information criterion, Root MSE Root mean squared error, PI Prediction interval

${ }^{\text {a }}$ Duration of symptoms was added in this model along with the predictors from the adj. R2 model

${ }^{\mathrm{b}}$ Model standard deviation 
knowingly or unknowingly have reported themselves as better or worse than they were $[64,65]$. Since this study was prospective, patients did not have knowledge of their outcome when reporting potential predictors. Thereby, it is unlikely that potential information problems in the predictors are dependent on the outcome variable, which minimizes the risk of bias. However, there is a risk of information bias, since it was not possible to blind participants to prognostic factors at the outcome assessment whereby reporting of outcome could be dependent on the predictors [11]. However, the risk is probably low since the patients did not have knowledge about the studied associations and there were 6 months between predictor- and outcome assessment. Further, we used a brief version of the pain catastrophizing scale along with subscales of the Örebro Musculoskeletal pain questionnaire, which might have affected the ability to capture the constructs of interest and their importance as predicters. However, the brief version of the pain catastrophizing scale has previously been validated [45] and the Örebro Musculoskeletal subscales were developed to capture the constructs of interest and have been validated in brief forms [40, 41].

We did not attempt to correct or impute, as missing values in candidate predictors were few and the distribution appeared random. Although we included a range of candidate predictors, other variables could have been included such as biomarkers, occupational factors, lifestyle factors and a series of other psychological factors $[8,13]$. Furthermore, information might have been lost when grouping the variables "professional educational level" and "employment status" into bigger groups. Also, a model accounting for interaction between variables could potentially have led to a different final prediction model. However, it was chosen not to consider interactions between variables since this study is not examining causal pathways $[11,66]$. Further, additional diagnostics and clinical tests could have been considered as candidate predictors, but as their performance, interpretability and information on diagnosis and prognosis is limited, such data was not collected in the present study [67-69].

We used a 6-month follow up though it could be argued that a follow-up period of 12 months would be preferable. However, 6 months was chosen, since treatment rarely exceeds this period of time, and previous studies of common musculoskeletal disorders shows that only little additional change happens beyond 6 months [70].

When using our results, it should be noted that this was an explorative multivariable study aiming to develop a prognostic model and not to explore individual factors, and therefore the parameters do not represent the factors' independent contribution to the prediction [14, 71]. Also, our population had a mean duration of symptoms of 29 months, and therefore our findings are probably not applicable to shoulder conditions of shorter duration as seen in primary care settings. Further, the modest recruitment rate could affect the generalisability of our findings, since only half of the invited patients agreed to participate.

When comparing models (for $n=220$ ), the root mean squared error only dropped from 20.6 in the model without independent variables to 17 in the final model, meaning that the residuals were only moderately less spread out in the final model. The final model explained $13 \%$ more of the variance in QuickDASH change than a model predicting change from only baseline QuickDASH. We believe that the collection of these extra variables contributing with $13 \%$ extra explained variance is justified by the fact that they are easy to collect along with QuickDASH scores. However, the model performance was modest, and the root mean squared error (model SD) was large meaning that the predictions were quite imprecise. Thus, there is limited clinical utility of the model in its current form on an individual prediction level. Therefore, possible contributions of other predictors should be explored in order to optimise the performance and preciseness of the model while a larger sample sizes could be considered.

By presenting a combination of variables with predictive ability, we hope that our study can guide future work on developing a model that can be used as a tool for stratified care. With such a tool, e.g. patients predicted to have satisfactory change scores at baseline can receive usual care, while patients predicted to have lower change scores can be directed to more intensive and specialised care options.

\section{Conclusion}

In this study, we aimed to develop a prognostic model to inform clinical decision making in order to improve outcomes for patients with persistent shoulder pain referred to physiotherapy rehabilitation. However, the precision of the predictions on an individual patient level was low. The final prognostic model included seven predictors explaining 33\% of the variance in QuickDASH change with a root mean squared error (model SD) of 17 points. Two of the included predictors were novel: Movement impairment classification based on diagnosis and health-related quality of life. Further work needs to be done in order to optimise the prognostic model including exploration of the contribution of other potential predictors before external validity can be examined along with the potential impact of the model in clinical practice. Thus, in its current form our model is more suitable for guiding future predictive work than for guiding clinical decision making. 


\section{Abbreviations}

QuickDASH: Quick Disabilities of the Arm, Shoulder and Hand; WHO-5: WHO mental wellbeing index; NPRS: Numeric pain rating scale; MIC: Minimal important change; Adjusted $\mathrm{R}^{2}$ : Adjusted coefficient of determination

\section{Supplementary Information}

The online version contains supplementary material available at https://doi. org/10.1186/s12891-021-04612-y.

Additional file 1. NON-RESPONDER ANALYSIS.

Additional file 2. MODEL DEVELOPMENT REPORT.

Additional file 3. SUPPLEMENTARY ANALYSES

\section{Acknowledgements}

The authors would like to thank the funding institution and the physiotherapists at the municipal outpatient rehabilitation clinics for participating in data collection. Also, they would like to thank the patients for their valuable participation.

\section{Authors' contributions}

MMR and DHC planned and designed the study. MMR performed the data analysis and drafted the manuscript. MMR, DHC and TABS contributed to interpretation of data and critical revision of the manuscript. All authors read and approved the final manuscript and agreed to full accountability for the content of this study.

\section{Funding}

Publication fee and all authors are funded by Department of Occupational Medicine, Regional Hospital West Jutland, University Research Clinic, Herning, Denmark.

\section{Availability of data and materials}

The dataset used and analysed during the current study is available from the corresponding author on reasonable request.

\section{Declarations}

\section{Ethics approval and consent to participate}

No ethics approval was needed, since participation did not affect referral and treatment pathways (Act on Research Ethics Review of Health Research Projects, October 2018) [26]. The study was performed in line with the ethical principles of the Helsinki declaration. All participants gave written informed consent to participate. The study was approved by the Danish Data Protection Agency and thus complied with the rules on protection of personal data (no 1-16-02-9-18).

\section{Consent for publication}

Not applicable.

\section{Competing interests}

The authors declare that they have no competing interests.

Received: 22 February 2021 Accepted: 15 August 2021

Published online: 27 August 2021

\section{References}

1. Luime JJ, Koes BW, Hendriksen IJ, Burdorf A, Verhagen AP, Miedema HS, et al. Prevalence and incidence of shoulder pain in the general population; a systematic review. Scand J Rheumatol. 2004;33(2):73-81. https://doi.org/1 0.1080/03009740310004667.

2. Djade CD, Porgo TV, Zomahoun HTV, Perrault-Sullivan G, Dionne CE. Incidence of shoulder pain in 40 years old and over and associated factors: a systematic review. Eur J Pain. 2020;24(1):39-50. https://doi.org/10.1002/ ejp.1482.

3. Kuijpers T, van Tulder MW, van der Heijden GJMG, Bouter LM, van der Windt DAWM. Costs of shoulder pain in primary care consulters: a prospective cohort study in The Netherlands. BMC Musculoskelet Disord. 2006;7:83.
4. Page MJ, O'Connor DA, Malek M, Haas R, Beaton D, Huang H, et al. Patients' experience of shoulder disorders: a systematic review of qualitative studies for the OMERACT Shoulder Core Domain Set. Rheumatology (Oxford, England). 2019;58(8):1410-21. https://doi.org/10.1093/rheumatology/kez046.

5. Chaudhury S, Gwilym SE, Moser J, Carr AJ. Surgical options for patients with shoulder pain. Nat Rev Rheumatol. 2010;6(4):217-26. https://doi.org/10.1038/ nrrheum.2010.25.

6. Sunhedsstyrelsen. National klinisk retningslinje for diagnostik og behandling af patienter med udvalgte skulderlidelser: Sundhedsstyrelsen; 2013. Available from: https://sundhedsstyrelsen.dk/da/udgivelser/2013/ /media/ ECDF89CE7B904A34A5EC8576B507289D.ashx. https://www.statsbiblioteket. dk/au/\#/search?query=recordID\%3A\%22sb_dbc_netpub_51842979\%22.

7. Christiansen DH, Frost P, Frich LH, Falla D, Svendsen SW. The use of physiotherapy among patients with subacromial impingement syndrome: impact of sex, socio-demographic and clinical factors. PLoS One. 2016;11(3): e0151077. https://doi.org/10.1371/journal.pone.0151077.

8. Burgess R, Mansell G, Bishop A, Lewis M, Hill J. Predictors of functional outcome in musculoskeletal healthcare: an umbrella review. Eur J Pain. 2019;24(1):51-70. https://doi.org/10.1002/ejp.1483.

9. Virta $L$, Joranger $P$, Brox Jl, Eriksson R. Costs of shoulder pain and resource use in primary health care: a cost-of-illness study in Sweden. BMC Musculoskelet Disord. 2012;13(1):17. https://doi.org/10.1186/1471-2474-13-17.

10. Croft P, Altman DG, Deeks JJ, Dunn KM, Hay AD, Hemingway H, et al. The science of clinical practice: disease diagnosis or patient prognosis? Evidence about "what is likely to happen" should shape clinical practice. BMC Med. 2015;13(1):20. https://doi.org/10.1186/s12916-014-0265-4

11. Moons KG, Royston P, Vergouwe $Y$, Grobbee DE, Altman DG. Prognosis and prognostic research: what, why, and how? Bmj. 2009;338(feb23 1):b375. https://doi.org/10.1136/bmj.b375.

12. Royston $\mathrm{P}$, Moons KG, Altman DG, Vergouwe Y. Prognosis and prognostic research: developing a prognostic model. Bmj. 2009;338(mar31 1):b604. https://doi.org/10.1136/bmj.b604

13. Steyerberg EW, Moons KG, van der Windt DA, Hayden JA, Perel P, Schroter $\mathrm{S}$, et al. Prognosis research strategy (PROGRESS) 3: prognostic model research. PLoS Med. 2013;10(2):e1001381. https://doi.org/10.1371/journal. pmed.1001381.

14. Kent P, Cancelliere C, Boyle E, Cassidy JD, Kongsted A. A conceptual framework for prognostic research. BMC Med Res Methodol. 2020;20(1):172. https://doi.org/10.1186/s12874-020-01050-7.

15. De Baets L, Matheve T, Meeus M, Struyf F, Timmermans A. The influence of cognitions, emotions and behavioral factors on treatment outcomes in musculoskeletal shoulder pain: a systematic review. Clin Rehabil. 2019;33(6): 980-91. https://doi.org/10.1177/0269215519831056.

16. Martinez-Calderon J, Meeus M, Struyf F, Miguel Morales-Asencio J, GijonNogueron G, Luque-Suarez A. The role of psychological factors in the perpetuation of pain intensity and disability in people with chronic shoulder pain: a systematic review. BMJ Open. 2018;8(4):e020703. https:// doi.org/10.1136/bmjopen-2017-020703.

17. Struyf F, Geraets J, Noten S, Meeus M, Nijs J. A multivariable prediction model for the chronification of non-traumatic shoulder pain: a systematic review. Pain Physician. 2016;19(2):1-10. https://doi.org/10.3 6076/ppj/2016.19.1

18. Chester R, Khondoker M, Shepstone L, Lewis JS, Jerosch-Herold C. Selfefficacy and risk of persistent shoulder pain: results of a Classification and Regression Tree (CART) analysis. Br J Sports Med. 2019;53(13):825-34. https://doi.org/10.1136/bjsports-2018-099450.

19. Kooijman MK, Barten DJ, Swinkels IC, Kuijpers T, de Bakker D, Koes BW, et al. Pain intensity, neck pain and longer duration of complaints predict poorer outcome in patients with shoulder pain--a systematic review. BMC Musculoskelet Disord. 2015;16(1):288. https://doi.org/10.11 86/s12891-015-0738-4

20. Chester R, Shepstone L, Daniell H, Sweeting D, Lewis J, Jerosch-Herold C. Predicting response to physiotherapy treatment for musculoskeletal shoulder pain: a systematic review. BMC Musculoskelet Disord. 2013;14(1): 203. https://doi.org/10.1186/1471-2474-14-203.

21. Braun C, Hanchard NC, Batterham AM, Handoll HH, Betthauser A. Prognostic models in adults undergoing physical therapy for rotator cuff disorders: systematic review. Phys Ther. 2016;96(7):961-71. https://doi.org/10.2522/ptj.2 0150475.

22. Martinez-Calderon J, Struyf F, Meeus M, Luque-Suarez A. The association between pain beliefs and pain intensity and/or disability in people with 
shoulder pain: a systematic review. Musculoskelet Sci Pract. 2018;37:29-57. https://doi.org/10.1016/.msksp.2018.06.010.

23. Chester R, Jerosch-Herold C, Lewis J, Shepstone L. Psychological factors are associated with the outcome of physiotherapy for people with shoulder pain: a multicentre longitudinal cohort study. Br J Sports Med. 2018;52(4): 269-75. https://doi.org/10.1136/bjsports-2016-096084.

24. Ebert JF, Huibers L, Christensen B, Christensen MB. Paper- or web-based questionnaire invitations as a method for data collection: cross-sectional comparative study of differences in response rate, completeness of data, and financial cost. J Med Internet Res. 2018;20(1):e24. https://doi.org/10.2196/jmir.8353.

25. Digitaliseringsstyrelsen. Statistik om Digital Post: Digitaliseringsstyrelsen; 2020. Available from: https://digst.dk/it-loesninger/digital-post/omloesningen/tal-og-statistik-om-digital-post/. Accessed Dec 2020.

26. Ethic DNCOBR. Act on research ethics review of health research projects. 2018. Available from: https://en.nvk.dk/rules-and-guidelines/act-on-researchethics-review-of-health-research-projects.

27. Collins GS, Reitsma JB, Altman DG, Moons KG. Transparent reporting of a multivariable prediction model for individual prognosis or diagnosis (TRIPOD): the TRIPOD statement. Bmj. 2015;350(jan07 4):g7594. https://doi. org/10.1136/bmj.g7594.

28. Moons KGM, Altman DG, Reitsma JB, loannidis JPA, Macaskill P, Steyerberg EW, et al. Transparent Reporting of a multivariable prediction model for Individual Prognosis Or Diagnosis (TRIPOD): explanation and elaboration. Ann Intern Med. 2015;162(1):W1-W73. https://doi.org/10.7326/M14-0698.

29. Angst F, Schwyzer HK, Aeschlimann A, Simmen BR, Goldhahn J. Measures of adult shoulder function: Disabilities of the Arm, Shoulder, and Hand Questionnaire (DASH) and its short version (QuickDASH), Shoulder Pain and Disability Index (SPADI), American Shoulder and Elbow Surgeons (ASES) Society standardized shoulder assessment form, Constant (Murley) Score (CS), Simple Shoulder Test (SST), Oxford Shoulder Score (OSS), Shoulder Disability Questionnaire (SDQ), and Western Ontario Shoulder Instability Index (WOSI). Arthritis Care Res. 2011;63(Suppl 11):S174-88.

30. Schonnemann JO, Eggers J. Validation of the Danish version of the QuickDisabilities of Arm, Shoulder and Hand Questionnaire. Dan Med J. 2016; 63(12):A5306.

31. Budtz CR, Andersen JH, de Vos Andersen NB, Christiansen DH Responsiveness and minimal important change for the quick-DASH in patients with shoulder disorders. Health Qual Life Outcomes. 2018;16(1):226. https://doi.org/10.1186/s12955-018-1052-2.

32. Lundquist CB, Dossing K, Christiansen DH. Responsiveness of a Danish version of the Disabilities of the Arm, Shoulder and Hand (DASH) questionnaire. Dan Med J. 2014;61(4):A4813.

33. Chester R, Jerosch-Herold C, Lewis J, Shepstone L. The SPADI and QuickDASH are similarly responsive in patients undergoing physical therapy for shoulder pain. J Orthop Sports Phys Ther. 2017;47(8):538-47. https://doi. org/10.2519/jospt.2017.7195.

34. Kennedy CA, Beaton DE, Smith P, Van Eerd D, Tang K, Inrig T, et al. Measurement properties of the QuickDASH (disabilities of the arm, shoulder and hand) outcome measure and cross-cultural adaptations of the QuickDASH: a systematic review. Qual Life Res. 2013;22(9):2509-47. https:// doi.org/10.1007/s11136-013-0362-4.

35. Bruls VE, Bastiaenen $\mathrm{CH}$, de Bie RA. Prognostic factors of complaints of arm, neck, and/or shoulder: a systematic review of prospective cohort studies. Pain. 2015;156(5):765-88. https://doi.org/10.1097/j.pain.0000000000000117.

36. Ludewig PM, Kamonseki DH, Staker JL, Lawrence RL, Camargo PR, Braman JP. Changing our diagnostic paradigm: movement system diagnostic classification. Int J Sports Phys Ther. 2017;12(6):884-93. https://doi.org/10.2 6603/ijspt20170884.

37. Bolton JE. Accuracy of recall of usual pain intensity in back pain patients. Pain. 1999;83(3):533-9. https://doi.org/10.1016/S0304-3959(99)00161-X.

38. Chiarotto A, Maxwell L, Ostelo RW, Boers M, Tugwell P, Terwee CB. Measurement properties of visual analogue scale, numeric rating scale, and pain severity subscale of the brief pain inventory in patients with low back pain: a systematic review. J Pain. 2019;20(3):245-63. https://doi.org/10.1016/j. jpain.2018.07.009.

39. Jensen MP, Turner JA, Romano JM, Fisher LD. Comparative reliability and validity of chronic pain intensity measures. Pain. 1999;83(2):157-62. https://doi.org/10.1016/S0304-3959(99)00101-3.

40. Oxfeldt M. Danish short form Örebro Musculoskeletal Pain Screening Questionnaire - translation, cross-cultural adaptation, and reliability [Student thesis]; 2017.
41. Linton SJ, Halldén K. Can we screen for problematic back pain? A screening questionnaire for predicting outcome in acute and subacute back pain. Clin J Pain. 1998;14(3):209-15. https://doi.org/10.1097/00002508-1 99809000-00007.

42. Hockings RL, McAuley JH, Maher CG. A systematic review of the predictive ability of the Orebro musculoskeletal pain questionnaire. Spine. 2008;33(15): E494-500. https://doi.org/10.1097/BRS.0b013e31817ba3bb.

43. Linton SJ, Nicholas M, MacDonald S. Development of a short form of the Örebro musculoskeletal pain screening questionnaire. Spine. 2011;36(22): 1891-5. https://doi.org/10.1097/BRS.0b013e3181f8f775.

44. Kilsgaard J. Prædiktive faktorer for udvikling af erhvervshindrende lænderygbesvær : afprøvning af et screeningsredskab. Århus: Master of Public Health, Aarhus Universitet; 2003.

45. Kent P, Mirkhil S, Keating J, Buchbinder R, Manniche C, Albert HB. The concurrent validity of brief screening questions for anxiety, depression, social isolation, catastrophization, and fear of movement in people with low back pain. Clin J Pain. 2014;30(6):479-89. https://doi.org/10.1097/AJP. 0000000000000010.

46. Sullivan MJL, Bishop S, Pivik J. The pain catastrophizing scale: development and validation; 1996. p. 524-32.

47. Fernandes L, Storheim K, Lochting I, Grotle M. Cross-cultural adaptation and validation of the Norwegian pain catastrophizing scale in patients with low back pain. BMC Musculoskelet Disord. 2012;13(1):111. https://doi.org/10.11 86/1471-2474-13-111.

48. Kjogx H, Zachariae R, Pfeiffer-Jensen M, Kasch H, Svensson P, Jensen TS, et al. Pain frequency moderates the relationship between pain catastrophizing and pain. Front Psychol. 2014;5:1421.

49. Topp CW, Østergaard SD, Søndergaard S, Bech P. The WHO-5 well-being index: a systematic review of the literature. Psychother Psychosom. 2015; 84(3):167-76. https://doi.org/10.1159/000376585.

50. Herdman M, Gudex C, Lloyd A, Janssen M, Kind P, Parkin D, et al. Development and preliminary testing of the new five-level version of EQ-5D (EQ-5D-5L). Qual Life Res. 2011;20(10):1727-36. https://doi.org/10.1007/s1113 6-011-9903-X.

51. Feng $Y$, Devlin N, Herdman M. Assessing the health of the general population in England: how do the three- and five-level versions of EQ-5D compare? Health Qual Life Outcomes. 2015;13(1):171. https://doi.org/10.11 86/s12955-015-0356-8.

52. Foundation ER. EQ-5D-5L User Guide. 2019.

53. Devlin N, Parkin D, Janssen B. Methods for Analysing and Reporting EQ-5D Data. Cham (CH): Springer Copyright 2020, The Editor(s) (if applicable) and The Author(s). This book is an open access publication. 2020.

54. van Hout B, Janssen MF, Feng YS, Kohlmann T, Busschbach J, Golicki D, et al. Interim scoring for the EQ-5D-5L: mapping the EQ-5D-5L to EQ-5D-3L value sets. Value Health. 2012;15(5):708-15. https://doi.org/10.1016/j.jval.2 012.02.008.

55. Pedersen CB. The Danish civil registration System. Scand J Public Health. 2011;39(7 Suppl):22-5. https://doi.org/10.1177/1403494810387965.

56. Harrell FE Jr, Lee KL, Mark DB. Multivariable prognostic models: issues in developing models, evaluating assumptions and adequacy, and measuring and reducing errors. Stat Med. 1996;15(4):361-87. https://doi.org/10.1002/ (SICI) 1097-0258(19960229)15:4<361::AID-SIM168>3.0.CO;2-4.

57. Royston P. Multivariable model-building: a pragmatic approach to regression analysis based on fractional polynomials for modelling continuous variables. Sauerbrei W, editor. Hoboken and Chichester: Wiley; 2008.

58. Theil H. Economic forecasts and policy. 2. rev. ed. ed. Theil H, editor. Amsterdam: North-Holland; 1961.

59. Sauerbrei $W$. The use of resampling methods to simplify regression models in medical statistics. J R Stat Soc: Ser C: Appl Stat. 1999;48(3):313-29. https:// doi.org/10.1111/1467-9876.00155

60. Franchignoni F, Vercelli S, Giordano A, Sartorio F, Bravini E, Ferriero G. Minimal clinically important difference of the disabilities of the arm, shoulder and hand outcome measure (DASH) and its shortened version (QuickDASH). J Orthop Sports Phys Ther. 2014;44(1):30-9. https://doi.org/1 0.2519/jospt.2014.4893

61. Mintken PE, Glynn P, Cleland JA. Psychometric properties of the shortened disabilities of the arm, shoulder, and hand questionnaire (QuickDASH) and numeric pain rating scale in patients with shoulder pain. J Shoulder Elb Surg. 2009;18(6):920-6. https://doi.org/10.1016/j.jse.2008.12.015.

62. Karel Y, Verhagen AP, Thoomes-de Graaf M, Duijn E, van den Borne MPJ, Beumer A, et al. Development of a prognostic model for patients with 
shoulder complaints in physical therapist practice. Phys Ther. 2017;97(1):7280. https://doi.org/10.2522/ptj.20150649.

63. Wijma AJ, Van Wilgen CP, Meeus M, Nijs J. Clinical biopsychosocial physiotherapy assessment of patients with chronic pain: the first step in pain neuroscience education. Physiother Theory Pract. 2016;32(5):368-84. https://doi.org/10.1080/09593985.2016.1194651.

64. Juul SB, Hammer B, Dahm CC, Rytter D. Epidemiologi og evidens. 3. udgave ed. Copenhagen: Munksgaard; 2017. p. 328.

65. Fonager K, Sabroe S. A comparative analysis of different methods for obtaining estimates of alcohol consumption in a Danish population survey. Scand J Public Health. 2001;29(4):256-62. https://doi.org/10.1177/1403494 8010290041001.

66. Hernán MA, Hsu J, Healy B. A second chance to get causal inference right: a classification of data science tasks. Chance. 2019;32(1):42-9. https://doi.org/1 $0.1080 / 09332480.2019 .1579578$

67. Wright AA, Wassinger CA, Frank M, Michener LA, Hegedus EJ. Diagnostic accuracy of scapular physical examination tests for shoulder disorders: a systematic review. Br J Sports Med. 2013;47(14):886-92. https://doi.org/1 0.1136/bjsports-2012-091573.

68. Hanchard NC, Lenza M, Handoll HH, Takwoingi Y. Physical tests for shoulder impingements and local lesions of bursa, tendon or labrum that may accompany impingement. Cochrane Database Syst Rev. 2013;(4):Cd007427.

69. D'Hondt NE, Kiers H, Pool JJM, Hacquebord ST, Terwee CB, Veeger D. Reliability of performance-based clinical measurements to assess shoulder girdle kinematics and positioning: systematic review. Phys Ther. 2017;97(1): 124-44. https://doi.org/10.2522/ptj.20160088.

70. Artus M, van der Windt $D$, Jordan KP, Croft PR. The clinical course of low back pain: a meta-analysis comparing outcomes in randomised clinical trials (RCTs) and observational studies. BMC Musculoskelet Disord. 2014;15:68.

71. Hayden JA, Cote P, Steenstra IA, Bombardier C. Identifying phases of investigation helps planning, appraising, and applying the results of explanatory prognosis studies. J Clin Epidemiol. 2008;61(6):552-60. https:// doi.org/10.1016/j.jclinepi.2007.08.005.

\section{Publisher's Note}

Springer Nature remains neutral with regard to jurisdictional claims in published maps and institutional affiliations.

Ready to submit your research? Choose BMC and benefit from:

- fast, convenient online submission

- thorough peer review by experienced researchers in your field

- rapid publication on acceptance

- support for research data, including large and complex data types

- gold Open Access which fosters wider collaboration and increased citations

- maximum visibility for your research: over $100 \mathrm{M}$ website views per year

At $\mathrm{BMC}$, research is always in progress.

Learn more biomedcentral.com/submissions 